American Journal of Pharmaceutical Education 2017; 81 (3) Article 50.

\title{
RESEARCH
}

\section{Exercise as a Stress Coping Mechanism in a Pharmacy Student Population}

\author{
Mathew C. Garber, PhD \\ Feik School of Pharmacy, University of the Incarnate Word, San Antonio, Texas \\ Submitted November 10, 2015; accepted March 30, 2016; published April 2017.
}

Objective. To assess the coping mechanisms used by pharmacy students and their relationship to perceived stress.

Methods. Data were gathered utilizing the Perceived Stress Scale (PSS10) and Brief COPE with the additional coping mechanisms of exercise and use of prescribed medications.

Results. A survey that was sent to 368 students had an $81 \%$ response rate. Perceived stress was significantly higher than standard populations, but consistent with other pharmacy student populations. The most frequently reported coping mechanisms were the adaptive strategies of active coping, acceptance and planning. Maladaptive strategies of behavioral disengagement, venting and self-blame were significantly associated with higher perceived stress scores and the new addition of an exercise coping mechanism significantly associated with lower perceived stress scores. Use of prescribed medications was not significantly associated with perceived stress levels.

Conclusion. Inclusion of exercise as a coping mechanism may be beneficial in similar populations.

Keywords: stress, exercise, student, PSS10, Brief COPE

\section{INTRODUCTION}

Health care profession curriculums have long been associated with high levels of student stress. ${ }^{1}$ Shapiro and colleagues found 600 articles discussing the importance of stress in medical education between 1966 and 1999. ${ }^{2}$ These levels of stress may be concerning because stress has been associated with depression, anxiety and increased illness. ${ }^{3-5}$ Even more integral for a health care student population is that stress may be associated with impaired decision-making skills, ${ }^{6}$ lower academic performance, ${ }^{3,7,8}$ and a reduction in empathy that may affect a student's ability to develop relationships with their patients. ${ }^{9}$

Specifically in pharmacy education, there have been several studies that examined stress and other related factors in students. Stress has been measured by several different instruments including the 10 question Perceived Stress Scale (PSS10), ${ }^{10-13} 14$ question Perceived Stress Scale (PSS14) ${ }^{14-18}$ Stress in Academic Life Scale (SALS), ${ }^{19}$ Student Life Stress Inventory (SLSI) ${ }^{20}$ Derogatis Stress Profile ${ }^{21}$ and other question sets. ${ }^{22-24}$ Several studies have measured health-related quality of life (HRQOL), ${ }^{11,13,20,23,25}$ finding that mental HRQOL was significantly lower in pharmacy students than their demographic equivalents. It has also been found that lower

Corresponding Author: Mathew C. Garber, Feik School of Pharmacy, University of the Incarnate Word, 4301 Broadway, PO Box 99, San Antonio, TX 78209. Tel. 210-883-1173.

E-mail: Garber@uiwtx.edu mental HRQOL scores were associated with increased stress (on various stress scales), ${ }^{11,13,20,23,25}$ lower perceived academic success, ${ }^{23}$ and increased use of maladaptive coping skills. ${ }^{11}$

Equally important is how an individual reacts to stress. Struthers and colleagues found that the negative effect between stress and academic performance could be mediated depending on the type of coping strategy employed. ${ }^{8}$ Coping strategies may be considered adaptive or maladaptive, with maladaptive coping strategies being associated with less favorable outcomes. ${ }^{26} \mathrm{We}$ explored the association between enrollment in a fulltime pharmacy school curriculum and stress as measured by the PSS10 assessment instrument. We also evaluated which coping mechanisms were used by pharmacy students to help manage their perceived stress using the Brief COPE. Additional coping mechanisms were included because they may be pertinent to this specific population.

\section{METHODS}

A web survey was sent in April 2015 to all (368) currently enrolled students at the Feik School of Pharmacy, University of the Incarnate Word. Participation was voluntary. We utilized the SurveyMonkey software (San Mateo, CA), an online electronic survey instrument which allows respondents to respond confidentially at their convenience. A faculty member announced the survey at each class and non-respondents were sent a reminder after three days. We 


\section{American Journal of Pharmaceutical Education 2017; 81 (3) Article 50.}

received Institutional Review Board approval prior to sending out the survey.

Perceived stress was measured using the previously validated 10 item Perceived Stress Scale (PSS10), ${ }^{27-29}$ which in some populations has been shown to have increased reliability over alternative item scales. ${ }^{30,31}$ Validity of the scale has been demonstrated by both biological changes such as higher cortisol levels and behavioral changes such as poor health practices. ${ }^{27} \mathrm{Re}-$ spondents answered 10 questions on how unpredictable, uncontrollable and overloaded they found their lives during the last month. Items were scored on a 0 to 4 Likert scale. Four of the 10 questions were worded in a positive manner and therefore were reverse scored in order to obtain the correct overall perceived stress score. The perceived stress scales have been successfully used in other pharmacy student populations, ${ }^{10,14,15,17,18,25}$ including the 10 item version. ${ }^{10-12}$ The authors of the scale specifically stated that it is not intended to be a diagnostic tool, so there are no "high stress" or "low stress" cutoffs. We can, however, compare to other populations. A mean score of 15.8 was found in a national survey of 2000 adults from the general population, administered in $2009 .^{27}$

To assess coping mechanisms in our student population, we utilized the Brief COPE. ${ }^{32}$ This scale asked two questions for each coping dimension measured. Respondents chose from $1=$ I haven't been doing this at all to $4=$ I've been doing this a lot. The Brief COPE has been used successfully in the past for pharmacy student populations. ${ }^{11,18}$ This scale typically measures 14 different dimensions but depending on the population being studied, dimensions may be omitted, replaced or more may be added to the scale. ${ }^{32}$

After observing the coping mechanisms measured within the Brief COPE, we assembled a panel of faculty and staff from the pharmacy school to discuss other coping mechanisms they believed might be pertinent. After a series of discussions and reviews of coping literature, two additional dimensions were hypothesized to have potential significance and were added. Exercise has been cited as a coping strategy for stress, ${ }^{33,34}$ including in pharmacy student populations. ${ }^{13,35}$ Also, while the Brief COPE asks respondents about alcohol and other drugs, it does not specifically ask about prescribed medications. A study by Frick and colleagues found that $11.6 \%$ of a pharmacy student population responded that they used prescription antianxiety medications or sleep aids for stress relief. ${ }^{35}$ The dimensions were represented by the two exercise questions and two prescription medication questions (Appendix 1). These questions were written in a way that was consistent with the Brief COPE.

Additional questions on the survey included a qualitative question that asked respondents what they have found to be an effective way to cope with stress. Analysis was performed using SPSS version 22 (Armonk, NY). ${ }^{36}$

\section{RESULTS}

The survey response rate (Table 1) for all enrolled students was $81 \%$, with specific class cohorts ranging from $64 \%$ to $95 \%$.

Utilizing the PSS10 (Cronbach's alpha .87), the mean perceived stress score for the student population was 18.2 , with a standard deviation of 6.8 (Table 2). Utilizing a oneway analysis of variance (ANOVA), perceived stress scores were found to differ significantly by class cohort $(p=.001)$. Specifically, third year students (P3) were more likely to report higher levels of stress than first year (P1) or fourth year (P4) students. Also P1 students were likely to report less perceived stress than second year (P2) students (Tukey test with a $95 \%$ confidence interval).

Table 3 displays the means and standard deviations for the 16 coping mechanisms by class that were measured with the most often reported at the top (active coping) and the least often reported coping mechanism at the bottom (use of prescribed medications). The created questions for exercise and prescribed medications were found to have a Cronbach's alpha of .95 and .081 respectively. The traditional coping strategies in the Brief COPE have been split into adaptive and maladaptive strategies. ${ }^{32,37}$ The adaptive strategies from the traditional scale are marked with an asterisk.

Reported use of coping strategies was generally consistent across class. The only exceptions were the coping mechanism of self-blame (ANOVA $p=.016$ ), which was reported slightly more often in P2 students than in P4 students (Tukey $p=.011$ ) and self-distraction (ANOVA $p=.01$ ), which was reported more often in P1 students than P4 students (Tukey $p=.011$ ).

Utilizing linear regression, all 16 coping mechanisms were evaluated against the students' perceived stress score (Table 4). Three of the traditional maladaptive coping mechanisms (behavioral disengagement, venting and selfblame) were found to be significant $(p<.05)$ in that students who reported using these maladaptive coping mechanisms also reported higher perceived stress. The added exercise coping mechanism was also found to be significant

Table 1. Survey Response Rate

\begin{tabular}{lccc}
\hline Cohort & Students & Respondents & Rate (\%) \\
\hline P1 students & 88 & 84 & 96 \\
P2 students & 91 & 81 & 89 \\
P3 students & 95 & 61 & 64 \\
P4 students & 94 & 72 & 77 \\
All students & 368 & 298 & 81 \\
\hline
\end{tabular}


American Journal of Pharmaceutical Education 2017; 81 (3) Article 50.

Table 2. Perceived Stress Score by Academic Year

\begin{tabular}{|c|c|c|c|c|c|c|c|}
\hline & \multirow[b]{2}{*}{ Mean (SD) } & \multirow[b]{2}{*}{ Tukey Post-hoc } & \multirow[b]{2}{*}{ Mean Difference } & \multirow[b]{2}{*}{ Std. Error } & \multirow[b]{2}{*}{$p$} & \multicolumn{2}{|c|}{ 95\% Confidence Interval } \\
\hline & & & & & & Lower Bound & Upper Bound \\
\hline \multirow[t]{3}{*}{ P1 students } & \multirow{3}{*}{$16.3(6.6)$} & 2nd Year & -2.7 & 1.0 & .05 & -5.4 & 0.0 \\
\hline & & 3rd Year & -4.3 & 1.1 & .00 & -7.2 & -1.4 \\
\hline & & 4th Year & -0.8 & 1.1 & .89 & -3.6 & 2.0 \\
\hline \multirow[t]{3}{*}{ P2 students } & \multirow{3}{*}{$19.0(7)$} & 1st Year & 2.7 & 1.0 & .05 & -0.0 & 5.4 \\
\hline & & 3rd Year & -1.6 & 1.1 & .48 & -4.6 & 1.3 \\
\hline & & 4th Year & 1.9 & 1.1 & .33 & -1.0 & 4.7 \\
\hline \multirow[t]{3}{*}{ P3 students } & \multirow{3}{*}{$20.6(6.4)$} & 1st Year & 4.3 & 1.1 & .00 & 1.4 & 7.2 \\
\hline & & 2nd Year & 1.6 & 1.1 & .48 & -1.3 & 4.6 \\
\hline & & 4th Year & 3.5 & 1.2 & .02 & 0.4 & 6.6 \\
\hline \multirow[t]{3}{*}{ P4 students } & \multirow{3}{*}{$17.1(6.6)$} & 1st Year & 0.8 & 1.1 & .89 & -2.1 & 3.6 \\
\hline & & 2nd Year & -1.9 & 1.1 & .33 & -4.7 & 1.0 \\
\hline & & 3rd Year & -3.5 & 1.2 & .02 & -6.6 & -0.4 \\
\hline
\end{tabular}

Negative means indicate lower levels of reported perceived stress in the indicated class population as compared to the other class

$(p<.01)$, where students who reported using exercise as a coping mechanism reported lower perceived stress. The dimension of prescribed medications had the lowest mean usage rate of any of the coping strategies. While not significantly correlated with perceived stress levels, $15 \%$ of respondents did indicate some use of this coping mechanism.

Regardless of other factors like sources of stress, a third of the variation in the perceived stress score was accounted for by utilized coping mechanisms $\left(\mathrm{R}^{2}=.36\right)$.

At the end of the survey, respondents were asked an open ended question of "What have you found to be an effective way to cope with stress." Of the 298 students, 213 (72\%) responded. Perceived effective coping mechanisms varied widely with some respondents mentioning several different coping mechanisms within their responses. Prevalent themes included physical exercise (87), socializing/talking to others (46), prayer (24), music/TV/movies (19), and sleep (17).

\section{DISCUSSION}

The higher levels of perceived stress and the variance based on class cohort are not unexpected. Several previous studies have been published with similar findings where pharmacy student populations have higher levels of perceived stress in years where the curriculum may be considered more rigorous. ${ }^{11,18}$

Coping skills have also been examined in pharmacy student populations using the Brief COPE. ${ }^{11,18}$ Our population reported utilizing the adaptive coping strategies more often than the maladaptive coping strategies. Consistent with our findings, Hirsch and colleagues measured

Table 3. Reported Coping Mechanisms Mean and Standard Deviation by Academic Year

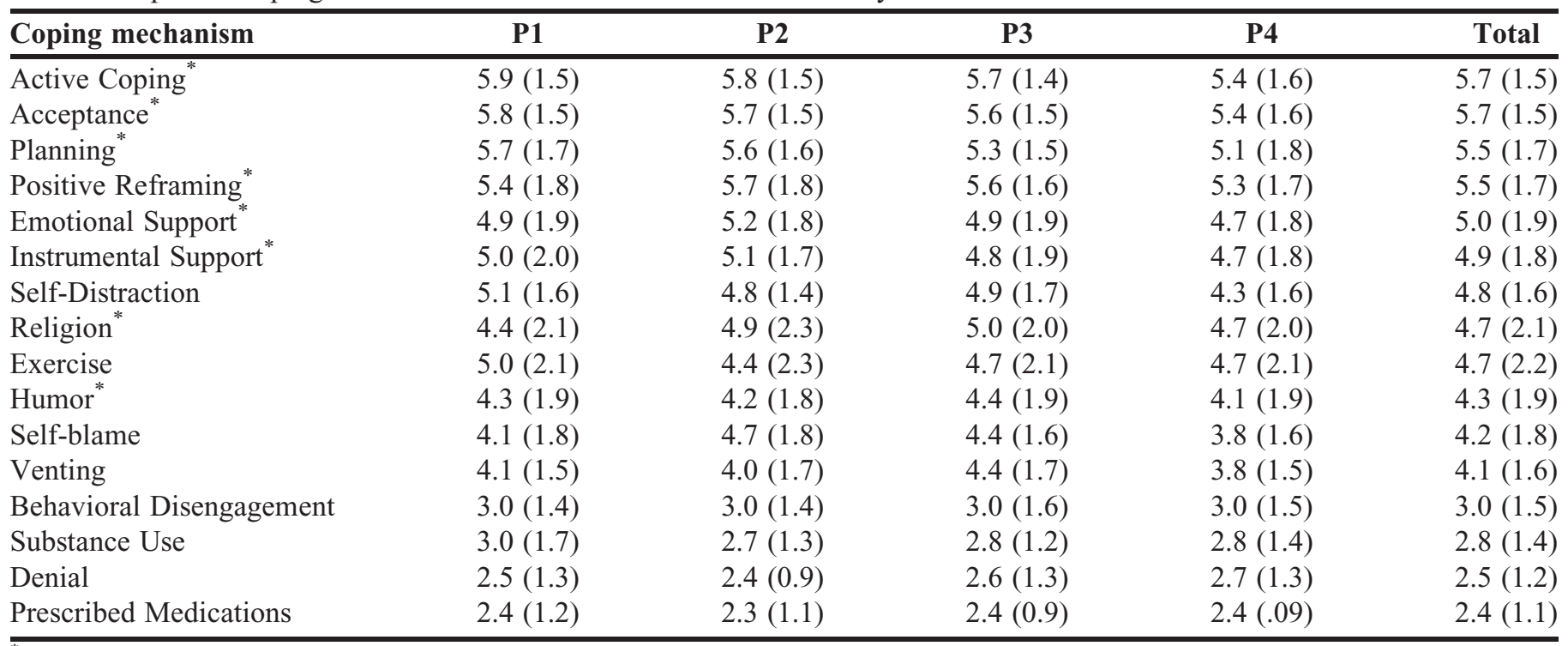

*Adaptive coping mechanisms

Scores from Brief COPE which range from 2-8. A low score of 2 would indicate that students had not reported using that coping mechanism at all 


\section{American Journal of Pharmaceutical Education 2017; 81 (3) Article 50.}

Table 4. Standardized Beta Coefficients $\left(\mathrm{R}^{2}=.33\right)$

\begin{tabular}{lcc}
\hline Coping mechanism & Beta Coefficient & $\boldsymbol{p}$ \\
\hline Self-blame & .28 & .00 \\
Behavioral Disengagement & .22 & .00 \\
Exercise & -.14 & .01 \\
Venting & .17 & .02 \\
Active Coping & -.12 & .10 \\
Religion & .09 & .14 \\
Instrumental Support & -.09 & .22 \\
Acceptance & .08 & .25 \\
Prescribed Medications & .07 & .25 \\
Planning & .07 & .33 \\
Self-distraction & -.06 & .33 \\
Positive Reframing & .05 & .45 \\
Substance Use & .05 & .46 \\
Humor & -.038 & .54 \\
Denial & -.03 & .61 \\
Emotional Support & .02 & .83 \\
\hline
\end{tabular}

across the three pre-clinical years of the pharmacy curriculum and found no difference in the use of maladaptive and adaptive coping strategies based on class and that students in all classes reported using adaptive coping strategies at twice the rate of maladaptive strategies. ${ }^{11}$ Mayer and Baugh also found that students reported using adaptive coping mechanisms more than maladaptive. ${ }^{18}$ This may be positive because using adaptive strategies may result in more favorable outcomes than using maladaptive strategies. ${ }^{38}$ What had not previously been examined is the role of exercise as a coping mechanism in this population.

Use of exercise as coping mechanism was extremely prevalent, with $75 \%$ of respondents stating that they were increasing exercise to some degree. Exercise has often been correlated with decreased stress; however, the studies have varied by population and sources of stress. ${ }^{33,34}$

As stated in Table 4, a statistically significant correlation was found between perceived stress and reported use of exercise as coping mechanism in our population. Another study of pharmacy students by Geslani and Gaebelein found that nearly half of the population used exercise as a coping mechanism. ${ }^{13}$ This association between stress and physical exercise has been shown in both laboratory and real-life situations, ${ }^{33,34}$ and multiple studies have found that physical activity correlated with lower levels of self-reported perceived stress. ${ }^{39,40}$ Specific to our student population, there have been a few studies that found a relationship between physical exercise and stress of academic-related activities. ${ }^{41,42}$

However, we need to be cautious to consider the direction of the potential causality in the correlation. Could it be that the students that perceived less stress believed they had more time to be physically active? Some studies have even found a decreased duration of physical activity when perceived stress was increased. ${ }^{41}$

So, is the perceived stress reducing the level of physical activity or is the physical activity decreasing the perceived stress? The literature review in 2009 found that stress moderation effects were consistently found in different samples and methodologies. ${ }^{43}$ For our population, a qualitative question from the survey may assist us. Respondents in our survey were asked a free text question "What have you found to be an effective way to cope with stress?" By far the most prevalent answer was along the lines of different forms of physical exercise (running, biking, working out), which occurred in the text of 87 different respondents. This indicates that students believe that physical exercise is an effective way to reduce or prevent stress and may make an argument for exercise having practical significance in reducing stress as well as being statistically significant.

\section{LIMITATIONS}

Perceived stress has been shown to be higher in female populations and to decrease with age. ${ }^{27}$ Our sample was younger and contained more females than the national sample we utilized as a benchmark. However, perceived stress in this population was still higher than the national female or youngest cohort. In addition, many of the questions within the survey are quite personal and respondents might be either reluctant to admit to negatively associated activities due to social desirability biases or concerns about potential ramifications. For example, one of the questions specifically asks about substance abuse. This population's institution has a policy of targeted drug screening which could result in expulsion, thus increasing reluctance to admit substance abuse even on a confidential survey.

It is unclear if the higher rates of perceived stress are more associated with an individual's personality rather than the curriculum they are currently undergoing. Tracking the same individuals as they move through the entire four-year curriculum may assist with this limitation.

While the overall response rate was high, it was noticeably lower for P3 and P4 students. Since the survey was voluntary, students with the highest degree of stress may have felt that they had the least amount of time to spend on other activities, like taking a survey. However, the nonrespondents may instead have had low stress and felt that the survey did not pertain to them, or they may have been influenced by some unknown factor unrelated to stress.

\section{CONCLUSION}

The creators of the Brief COPE have stated the need to adapt the scale to the specific population. We believe that inclusion of exercise as coping mechanism is 


\section{American Journal of Pharmaceutical Education 2017; 81 (3) Article 50.}

appropriate for this population. We also believe that students who regularly participate in physical exercise should be encouraged to continue this practice as it may assist with perceived stress while in a rigorous academic program.

\section{ACKNOWLEDGMENTS}

The author would like to acknowledge the Feik School of Pharmacy stress assessment committee (Dr. Mosley, Dr. Copeland and Ms. Seeger) for their insight; Dr. Linn and Ms. Zertuche for their methodological assistance; and Dr. Maize and Ms. Etter for facilitating and administering the survey.

\section{REFERENCES}

1. Bjorksten O, Sutherland S, Miller C, Stewart T. Identification of medical student problems and comparison with those of other students. J Med Educ. 1983;58(10):759-767.

2. Shapiro SL, Shapiro DE, Schwartz GE. Stress management in medical education: a review of the literature. Acad Med. 2000;75 (7):748-759.

3. Silverstein ST, Kritz-Silverstein D. A longitudinal study of stress in first-year dental students. J Dent Educ. 2010;74(8):836-848.

4. Glaser R, Kiecolt-Glaser JK. Stress-induced immune dysfunction: implications for health. Nat Rev Immunol. 2005;5(3):243-251.

5. Hammen C. Stress and depression. Annu Rev Clin Psychol. 2005;1:293-319.

6. Klein G. The effect of acute stressors on decision making. In: Stress and human performance. Mahwah, N.J.: Lawrence Erlbaum Associates; 1996:49-88.

7. Stewart SM, Lam TH, Betson CL, Wong CM, Wong AM. A prospective analysis of stress and academic performance in the first two years of medical school. Med Educ. 1999;33(4):243-250. 8. Struthers CW, Perry RP, Menec VH. An examination of the relationship among academic stress, coping, motivation, and performance in college. Res High Educ. 2000;41(5):581-592. 9. Neumann M, Edelhäuser F, Tauschel D, et al. Empathy decline and its reasons: a systematic review of studies with medical students and residents. Acad Med. 2011;86(8):996-1009.

10. Gallagher CT, Mehta ANV, Selvan R, et al. Perceived stress levels among undergraduate pharmacy students in the UK. Curr Pharm Teach Learn. 2014;6(3):437-441.

11. Hirsch JD, Do AH, Hollenbach KA, Manoguerra AS, Adler DS. Students' health-related quality of life across the preclinical pharmacy curriculum. Am J Pharm Educ. 2009;73(8):Article 147. 12. Votta RJ, Benau EM. Predictors of stress in doctor of pharmacy students: results from a nationwide survey. Curr Pharm Teach Learn. 2013;5(5):365-372.

13. Geslani GP, Gaebelein CJ. Perceived stress, stressors, and mental distress among doctor of pharmacy students. Soc Behav Pers. 2013;41(9):1457-1468.

14. Ab Hadi H, Awadh A. Study of psychological stress and acne vulgaris among pharmacy students. Value Health. 2015;18(3):A179-A180. 15. Frick LJ, Frick JL, Coffman RE, Dey S. Student stress in a threeyear doctor of pharmacy program using a mastery learning educational model. Am J Pharm Educ. 2011;75(4):Article 64. 16. Marshall LL, Allison A, Nykamp D, Lanke S. Perceived stress and quality of life among doctor of pharmacy students. Am J Pharm Educ. 2008;72(6):Article 137.
17. S Noor, Ghadz, SMS, Hanafiah NHM. Perceived stress level assessment among final year pharmacy students during pharmacy based clerkship. Int $J$ Pharm Teach Pract. 2010;1(2):20-23.

18. Maynor LM, Carbonara G. Perceived stress, academic self concept, and coping strategies of pharmacy students. Int J Pharm Educ Pract. 2012;9(1):1-9.

19. Alzaeem AY, Sulaiman SAS, Gillani SW. Assessment of the validity and reliability for a newly developed stress in academic life scale (SALS) for pharmacy undergraduates. Int J Col Res Internal Med Pub Health. 2010;2(7):239-256.

20. Gupchup GV, Borrego ME, Konduri N. The impact of student life stress on health related quality of life among doctor of pharmacy students. Coll Stud J. 2004;38(2):292.

21. Dutta A, Pyles M, Miederhoff P. Measuring and understanding stress in pharmacy students. In: Landow M, ed. Stress and Mental Health of College Students. New York, NY: Nova Science Publishers; 2006:1-28.

22. Gonzalez-Ramirez MT, Rodriguez-Ayan MN, Hernandez RL. The perceived stress scale (PSS): normative data and factor structure for a large-scale sample in Mexico. Span J Psychol. 2013;16:E47. 23. Konduri N, Gupchup GV, Borrego ME, Worley-Louis M. Assessment of the reliability and validity of a stress questionnaire for pharmacy administration graduate students. Coll Stud J. 2006;40(1): 78-90.

24. Stecker T. Well-being in an academic environment. Med Educ. 2004;38(5):465-478.

25. Marshall LL, Allison A, Nykamp D, Lanke S. Perceived stress and quality of life among doctor of pharmacy students. Am J Pharm Educ. 2008;72(6):Article 137.

26. Jalbrzikowski M, Sugar CA, Zinberg J, Bachman P, Cannon TD, Bearden CE. Coping styles of individuals at clinical high risk for developing psychosis. Early Interv Psychiatry. 2014;8(1):68-76. 27. Cohen S, Janicki-Deverts D. Who's stressed? Distributions of psychological stress in the United States in probability samples from 1983, 2006, and 2009. J Appl Soc Psychol. 2012;42(6):1320-1334. 28. Cohen S, Kamarck T, Mermelstein R. A global measure of perceived stress. J Health Soc Behav. 1983;24(4):385-396.

29. Cohen S. Perceived stress in a probability sample of the United States. In: Spacapan, Shirlynn, ed.; Oskamp, Stuart, ed. The Social Psychology of Health. The Claremont Symposium on Applied Social Psychology. Thousand Oaks, CA: US Sage Publications Inc; 1988: 31-67. 30. Lee E. Review of the psychometric evidence of the perceived stress scale. Asian Nurs Res. 2012;6(4):121-127.

31. Lesage FX, Berjot S, Deschamps F. Psychometric properties of the French versions of the perceived stress scale. Int J Occup Med Environ Health. 2012;25(2):178-184.

32. Carver CS. You want to measure coping but your protocol's too long: consider the brief COPE. Int J Behav Med. 1997;4(1):92-100. 33. Salmon P. Effects of physical exercise on anxiety, depression, and sensitivity to stress: a unifying theory. Clin Psychol Rev. 2001;21(1):33-61. 34. Rostad FG, Long BC. Exercise as a coping strategy for stress: a review. Int J Sport Psychol. 1996;27(2):197-222.

35. Lehner P, Seyed-Solorforough M, Connor MF, Sak S, Mullin T. Cognitive biases and time stress in team decision making. IEEE Trans Systems, Man and Cybernetics - Part A: Systems and Humans. 1997;27(5):698-703.

36. IBM Corp. IBM SPSS statistics for windows. Released 2013;22.0.

37. Carver CS, Scheier MF, Weintraub JK. Assessing coping strategies: a theoretically based approach. J Pers Soc Psychol. 1989;56(2):267-283. 


\section{American Journal of Pharmaceutical Education 2017; 81 (3) Article 50.}

38. Carver CS, Pozo C, Harris SD, et al. How coping mediates the effect of optimism on distress: a study of women with early stage breast cancer. J Pers Soc Psychol. 1993;65(2):375.

39. Gerber M, Brand S, Herrmann C, Colledge F, HolsboerTrachsler E, Puehse U. Increased objectively assessed vigorousintensity exercise is associated with reduced stress, increased mental health and good objective and subjective sleep in young adults. Physiol Behav. 2014;135:17-24.

40. Berger BG, Friedmann E, Eaton M. Comparison of jogging, the relaxation response, and group interaction for stress reduction. $J$ Sport Exerc Psychol. 1988;10(4):431-447.

Appendix 1. Questions Added to Brief COPE

Exercise

I've been increasing my exercise to make myself feel better;

I've been more physically active (eg, running, biking, lifting weights, etc.) to take my mind off what is happening.

\section{Prescribed medications}

I've been turning to medications prescribed to me to escape; I've increased my use of medication prescribed to me to make myself feel better.
41. Steptoe A, Wardle J, Pollard TM, Canaan L, Davies GJ. Stress, social support and health-related behavior: a study of smoking, alcohol consumption and physical exercise. J Psychosom Res. 1996;41(2):171-180.

42. Haugland S, Wold B, Torsheim T. Relieving the pressure? The role of physical activity in the relationship between school-related stress and adolescent health complaints. Res Q Exerc Sport. 2003;74 (2):127-135

43. Gerber M, Püehse U. Do exercise and fitness protect against stress-induced health complaints: a review of the literature. Scand $J$ Public Health. 2009;37(8):801-819. 